Check for updates

1 University of Nottingham, Nottingham, UK

2 University of Manchester, Manchester, UK

3 De Montfort University, Leicester, UK

Correspondence to H.Sewell herb.sewell@nottingham.ac.uk

Cite this as: BMJ 2020;371:m4838 http://dx.doi.org/10.1136/bmj.m4838 Published: 17 December 2020

\section{Covid-19 vaccines: delivering protective immunity}

\author{
Evidence supports both $T$ and $B$ cell responses to the three leading vaccines \\ Herb F Sewell, ${ }^{1}$ Raymond M Agius, ${ }^{2}$ Denise Kendrick, ${ }^{1}$ Marcia Stewart ${ }^{3}$
}

Early in the covid-19 pandemic it was unclear whether and how individuals and populations would develop protective and enduring immunity against SARS-CoV-2, either after infection or vaccination. Initial focus was on defining virus neutralising antibodies from B cells after infection. Early reports indicated that such antibodies decline substantially over less than six months, raising questions about how long protective immunity might last following infection. T cells are also known to be important in protecting against many viral infections through processes known as cellular immunity. Defining the roles of $\mathrm{T}$ cells in covid-19 became a central focus for investigation. ${ }^{1}$

Both memory $\mathrm{T}$ cell and $\mathrm{B}$ cell responses specific to SARS-CoV $-2^{23}$ have now been found up to six months after infection. Similar T and B cell responses might be expected following vaccination, and may account for the good efficacy suggested by interim results from the three most advanced vaccine candidates. ${ }^{4-6}$ All three vaccines-two mRNA vaccines (Pfizer-BioNTech and Moderna) and a DNA vaccine (Oxford-AstraZeneca)-encode genetic information, enabling the body to produce a viral antigen (the spike protein) that stimulates an immune response. In phase I and II trials, all three vaccines induced neutralising antibodies to the spike protein and also cellular immune responses. ${ }^{7}{ }^{8}$ Interim data from phase III trials suggest all three vaccines protect against symptomatic infection with SARS-CoV-2.

Trials of the two RNA vaccines report efficacies above $90 \%$. The viral vector DNA vaccine trial

(Oxford-AstraZeneca) reported an average of $70 \%$ efficacy, ranging from $62-90 \%$ in subgroups receiving different vaccination dosages. ${ }^{5}$ Both the

Oxford-AstraZeneca group and Pfizer-BioNTech group have published their phase III trials in peer reviewed journals (Lancet and New England Journal of Medicine respectively ${ }^{6}$ ), confirming efficacy claims made in earlier press releases. However, the Moderna mRNA vaccine group has so far released only limited data. Medicines regulators in the UK and US have now approved the Pfizer-BioNTech vaccine for emergency use after reviewing all the short term safety, efficacy, and quality data submitted by the manufacturer.

\section{Cellular immunity}

What role might immune cellular responses play in the development of immunity to SARS-CoV-2 and what are the implications for vaccines? As T cells recognise and respond to viral antigens they produce many protective reactions and effector molecules. One such molecule is the cytokine interferon $\gamma$, secreted by CD4+ and CD8+ T cells and their memory cells. This can be measured in laboratory tests such as the ELISpot assay as a means of documenting specific $\mathrm{T}$ cell responses to viral antigens. ${ }^{9-11}$

Individuals with high antibody levels after infection have been shown to have a high number of SARS-CoV-2 specific T cells secreting interferon $\gamma \cdot{ }^{10}$ $\mathrm{T}$ cells producing interferon $\gamma$ have also been detected a median of 75 days after PCR confirmed covid-19 in people with undetectable SARS-CoV-2 antibodies, ${ }^{10}$ suggesting immunity is partly mediated and maintained by memory T cells. Finally, a preprint of a recent study of 100 people with a history of asymptomatic or mild covid-19 reports T cell mediated immune responses lasting for at least six months in all participants. ${ }^{11}$

These studies and others ${ }^{310} 12$ offer strong evidence that $\mathrm{T}$ cell immune responses are sustained, even in the face of declining or undetectable antibodies, implying that some immunity persists. It is possible, but as yet unconfirmed, that immunity might last even longer, as T cell responses to SARS-CoV-1 and MERS-CoV have been found several years after infection. ${ }^{13}$ The evidence from new studies, interim results from phase III vaccine trials, and previous data from phase I and phase II trials support the notion that memory $\mathrm{T}$ cell responses to the vaccines, along with B cell antibody responses, should provide good and possibly enduring immunity to SARS-Cov-2. This, together with continuing public health measures, should help lay a pathway out of the pandemic.

High vaccine uptake will be critical to achieving individual and population immunity. Equitable global access to effective vaccines is also essential. Open debate and public education campaigns will be required to build trust and counter vaccine hesitancy ${ }^{14}$ and effective pharmacovigilance ${ }^{15}$ will be needed to monitor long term safety. Continued research and development will be needed to stay ahead of potentially consequential viral mutations, ${ }^{16}$ which could have negative consequences for covid-19 vaccines.

The scientific achievements since SARS-CoV-2 was first identified less than year ago give grounds for optimism that within a reasonable timeframe we should, globally, be able to successfully manage this pandemic. We should also have learnt enough to prepare for-if not to avert-future epidemics and pandemics.

Competing interests: The BM/has judged that there are no disqualifying financial ties to commercial companies. The authors declare no other interests. The BM policy on financial interests is here: https://www.bmj.com/sites/default/files/attachments/resources/2016/03/16-current-bmj-education-coi-form.pdf.

Provenance and peer review: Commissioned; not externally peer reviewed. 
1 Sewell HF, Agius RM, Stewart M, Kendrick D. Cellular immune responses to covid-19. BMJ 2020;370:m3018. doi: 10.1136/bmj.m3018 pmid: 32737031

2 Rodda LB, Netland J, Shehata L, etal. Functional SARS-CoV-2-specific immune memory persists after mild COVID-19.medRxiv2020:2020.08.11.20171843. [Preprint.] https://www.medrxiv.org/content/10.1101/2020.08.11.20171843V2

3 Dan JM, Mateus J, Kato Y, etal. Immunological memory to SARS-CoV-2 assessed for greater than six months after infection. bioRxiv 2020 [Preprint.] https://www.biorxiv.org/content/10.1101/2020.11.15.383323v1.full.pdfdoi: 10.1101/2020.11.15.383323

4 Mahase E. Covid-19: What do we know about the late stage vaccine candidates?BMJ 2020;371:m4576. doi: 10.1136/bmj.m4576 pmid: 33234507

5 Ramasamy MN, Minassian AM, Ewer KJ, etalOxford COVID Vaccine Trial Group. Safety and immunogenicity of ChAdOX1 nCoV-19 vaccine administered in a prime-boost regimen in young and old adults (COVO02): a single-blind, randomised, controlled, phase 2/3 trial. Lancet 2020;S0140-6736(20)32466-1. doi: 10.1016/S0140-6736(20)32466-1 pmid: 33220855

6 Polack FP, Thomas SJ, Kitchin N, etal. C4591001 Clinical Trial Group. Safety and efficacy of the BNT162b2 mRNA covid-19 vaccine. N Engl J Med 2020. doi: 10.1056/NEJMoa2034577. pmid: 33301246

7 Zhu F-C, Guan X-H, Li Y-H, etal. Immunogenicity and safety of a recombinant adenovirus type-5-vectored COVID-19 vaccine in healthy adults aged 18 years or older: a randomised, double-blind, placebo-controlled, phase 2 trial. Lancet 2020;396:479-88. doi: 10.1016/S0140-6736(20)31605-6 pmid: 32702299

8 Folegatti PM, Ewer KJ, Aley PK, etalOxford COVID Vaccine Trial Group. Safety and immunogenicity of the ChAdOX1 nCoV-19 vaccine against SARS-CoV-2: a preliminary report of a phase 1/2, single-blind, randomised controlled trial. Lancet 2020;396:467-78. doi: 10.1016/S0140-6736(20)31604-4 pmid: 32702298

$9 \mathrm{Ni}$ L, Ye F, Cheng ML, etal. Detection of SARS-CoV-2-Specific Humoral and cellular immunity in covid-19 convalescent individuals. Immunity 2020;52:971-977.e3. doi: 10.1016/j.immuni.2020.04.023 pmid: 32413330

10 Schwarzkopf S, Krawczyk A, Knop D, etal. Cellular immunity in COVID-19 convalescents with PCR-confirmed infection but with undetectable SARS-CoV-2-specific IgG. Emerg Infect Dis 2020;27. doi: 10.3201/eid2701.203772. pmid: 33058753

11 Zuo J, Dowell A, Pearce H, etal. Robust SARS-CoV-2-specific T-cell immunity is maintained at 6 months following primary infection.BioRxiv 2020:2020.11.01.362319v1 [Preprint]. www.biorxiv.org/content/10.1101/2020.11.01.362319v1

12 Peng Y, Mentzer AJ, Liu G, etalOxford Immunology Network Covid-19 Response T cell ConsortiumISARIC4C Investigators. Broad and strong memory $\mathrm{CD}^{+}$and $\mathrm{CD} 8^{+} \mathrm{T}$ cells induced by SARS-CoV-2 in UK convalescent individuals following COVID-19. Nat Immuno/2020;21:1336-45. doi: 10.1038/s41590-020-0782-6 pmid: 32887977

13 Sariol A, Perlman S. Lessons for covid-19 immunity from other coronavirus infectionS. Immunity 2020;53:248-63. doi: 10.1016/j.immuni.2020.07.005 pmid: 32717182

14 Lazarus JV, Ratzan SC, Palayew A, etal. A global survey of potential acceptance of a COVID-19 vaccine. Nat Med 2020. doi: 10.1038/s41591-020-1124-9 pmid: 33082575

15 Chandler RE. Modernising vaccine surveillance systems to improve detection of rare or poorly defined adverse events. BMJ2019;365:12268. doi: 10.1136/bmj.I2268 pmid: 31151960

16 Thomson EC, Rosen LE, Shepherd JG, etal. The circulating SARS-CoV-2 spike variant N439K maintains fitness while evading antibody-mediated immunitybioRxiv 2020 [Preprint.]

This article is made freely available for use in accordance with BMJ's website terms and conditions for the duration of the covid-19 pandemic or until otherwise determined by BMJ. You may use, download and print the article for any lawful, non-commercial purpose (including text and data mining) provided that all copyright notices and trade marks are retained. 